\title{
Microalbuminuria: Correlation With Prevalence and Severity of Coronary Artery Disease in Non-Diabetics
}

\author{
Pravin Kumar Jha ${ }^{a}$, Tony Ete ${ }^{\mathrm{a}}$, Amit Malviya ${ }^{\mathrm{a}}$, Chandra Kumar Das ${ }^{\mathrm{a}}$, \\ Swapan Kumar Saha ${ }^{\mathrm{a}}$, Dhanjit Nath ${ }^{\mathrm{a}}$, Manish Kapoora, b, \\ Animesh Mishra ${ }^{\text {a }}$
}

\begin{abstract}
Background: Previous studies have shown that microalbuminuria (MAU) is an independent risk factor for cardiovascular diseases in diabetics, hypertensive patients and in the general population. However, the correlation of MAU with the severity of coronary artery disease (CAD) in non-diabetic patients has not been addressed in detail. This study aimed to investigate the relationship between MAU and severity of angiographically confirmed CAD in non-diabetic patients.
\end{abstract}

Methods: This was a cross-sectional study, which included 90 nondiabetic patients with documented CAD by coronary angiography. The ratio of urine albumin to creatinine was used to define MAU and severity of CAD was estimated using SYNTAX score. Patients were divided into two groups: group I that included patients without MAU and group II that included patients with MAU.

Results: Out of 90 non-diabetic CAD patients, 62 (68.9\%) were in group I (MAU negative) and 28 (31.1\%) were in group II (MAU positive). There was statistically significant difference in the median SYNTAX score between the groups ( $21 \mathrm{vs.} 28, \mathrm{P}<0.001)$. The prevalences of double vessel CAD and triple vessel CAD were significantly higher in MAU positive group. There was a strong relationship between the presence of MAU and the extent and complexity of CAD $(\mathrm{r}=0.094 ; \mathrm{P}<0.001)$.

Conclusion: Thus, we conclude that patients with MAU have more severe angiographically detected CAD than those without MAU, and MAU exhibits a significant association with the presence and severity of CAD.

Keywords: Non-diabetics; Microalbuminuria; Coronary artery disease

Manuscript submitted October 20, 2016, accepted December 9, 2016

a Department of Cardiology, North Eastern Indira Gandhi Regional Institute of Health and Medical Sciences, Mawdiangdiang, Shillong, India

${ }^{b}$ Corresponding Author: Manish Kapoor, Department of Cardiology, North Eastern Indira Gandhi Regional Institute of Health and Medical Sciences, Mawdiangdiang, Shillong, India. Email: drmanishkshillong@gmail.com

doi: https://doi.org/10.14740/jocmr2785w

\section{Introduction}

Coronary artery disease (CAD) is a major cause of death and disability in both developed and developing countries. Advancing age, male sex, hypertension, diabetes mellitus, dyslipidemia and cigarette smoking are the independent risk factors for CAD [1], but they do not entirely explain the variation in cardiovascular disease incidence and mortality. Therefore, additional risk factors have been proposed to better identify patients potentially at risk for CAD, and urinary albumin is a promising candidate. Since the first description in 1974 [2], the presence of subclinical increases in urinary albumin excretion (UAE) has attracted attention, but much remains to be understood about the role of microalbuminuria (MAU) in nondiabetic individuals.

An increasing number of studies in different patient populations have reported that MAU is independently associated with cardiovascular morbidity and mortality in patients with diabetes [3], hypertension [4] and in the general population [5]. On the contrary, some other studies have also shown that this correlation is independent of renal function, hypertension, and diabetes $[6,7]$. Data from several studies have demonstrated that MAU predicts development of ischemic cardiovascular events related to the development of atherosclerosis [8]. MAU is a common phenomenon in patients with cardiovascular disease worldwide. The term MAU is defined as urinary albumin levels of more than or equal to 30 - $300 \mathrm{mg} / 24 \mathrm{~h}$ in $24-\mathrm{h}$ urine collection or albumin/creatinine ratio (ACR) of $>30-300 \mathrm{mg} / \mathrm{g}$ creatinine in random spot urine sample.

How MAU may be related to the development of atherosclerotic vascular disease is yet unclear. The currently accepted pathophysiological mechanism involves local injury to vascular smooth muscle cells and endothelium leading to cell proliferation and increase in vascular permeability $[9,10]$. It is also reported that patients with MAU have a greater atherosclerosis burden in the form of multi-vessel CAD than in patients without it [11]. The association between albuminuria and cardiovascular events is well recognized [12], but few studies have addressed its correlation with the severity of CAD. This study was designed to investigate the relation between MAU, and the prevalence and severity of angiographically confirmed $\mathrm{CAD}$ in non-diabetic patients. 
Table 1. Demographic and Clinical Characteristics of Patients

\begin{tabular}{llll}
\hline Variable & Group I (MAU negative) $(\mathbf{n}=\mathbf{6 2})$ & Group II (MAU positive) $(\mathrm{n}=\mathbf{2 8})$ & P-value \\
\hline Age (years) & $53 \pm 3.25$ & $54 \pm 2.75$ & 0.100 \\
Sex & & & 0.994 \\
$\quad$ Males, n (\%) & $40(64.5 \%)$ & $19(67.9 \%)$ & $9(32.1 \%)$ \\
$\quad$ Females, n (\%) & $22(35.5 \%)$ & $17(60 \%)$ & 0.998 \\
Hypertension, n (\%) & $38(61.2 \%)$ & $10(35.7 \%)$ & 0.513 \\
Hypercholesterolemia, n (\%) & $22(35.4 \%)$ & $9(32.1 \%)$ & 0.999 \\
Smokers, n (\%) & $21(33.8 \%)$ & $3(10.7 \%)$ & 0.999 \\
Family history of CAD, n (\%) & $7(11.3 \%)$ & $85 \pm 3.75$ & 0.499 \\
Fasting blood sugar (mg/dL) & $86 \pm 4$ & $1.08 \pm 0.047$ & 0.254 \\
Serum creatinine (mg/dL) & $1.07 \pm 0.062$ & & \\
\hline
\end{tabular}

Numerical data expressed as median $\pm I Q R$. CAD: coronary artery disease.

\section{Materials and Methods}

\section{Study population}

The present cross-sectional study was done among enrolled non-diabetic patients who were suspected for CAD and who underwent elective coronary angiography at NEIGRIHMS, Meghalaya, India, between January 2014 and August 2015. A total of 90 patients were enrolled during study period. Coronary angiography and assessment of MAU were done at the same time. Exclusion criteria were: diabetes, recent history of acute myocardial infarction or percutaneous transluminal coronary angioplasty, congestive heart failure, malignant diseases, presence of active infection, renal failure, serum creatinine level over $2 \mathrm{mg} / \mathrm{dL}$ or glomerular filtration rate (GFR) below $30 \mathrm{dL} / \mathrm{min}$, using angiotensin-converting enzyme inhibitors (ACEIs) or angiotensin II receptor blockers (ARBs). Initial evaluation of the patients by history and clinical examination were performed and recorded in the preformed data collection sheet. The data were collected on demographic and major cardiovascular risk factors including age, hypertension, diabetes mellitus, smoking and family history of CAD. Baseline laboratory investigations, e.g. complete blood count, chest roentgenogram, serum creatinine, serum electrolytes, fasting blood sugar, fasting lipid profile, electrocardiogram, and echocardiography, were done. Written consents were taken from all the patients. This study has been approved by institutional review committee and institute medical ethical committee.

\section{Measurement of MAU}

We collected a morning random urine sample before coronary artery catheterization. Urinary albumin concentration was measured by turbidimetric immunological technique, using Beckman Coulter AU 2700 auto-analyzer. Urine ACR was calculated and reported as $\mathrm{mg} / \mathrm{g}$ creatinine. Patients with albumin levels less than $30 \mathrm{mg} / \mathrm{g}$ of creatinine were defined as having normoalbuminuria, those with albumin levels $30-300 \mathrm{mg} / \mathrm{g}$ as having MAU.

\section{Coronary angiography (assessment for coronary artery atherosclerotic disease)}

The diagnostic procedure was performed by an experienced interventional cardiologist by using a Philips AlluraXper system via right femoral/right radial artery after performing local anesthesia with xylocaine. Interpretation of coronary angiogram was reviewed and angiographic severity of coronary artery disease was assessed by the number of vessels involved and SYNTAX score. The SYNTAX score is a tool to score complexity of CAD as follows: low $(0-22)$, which is suitable for percutaneous coronary intervention (PCI), intermediate (23 - 32), which is suitable for either PCI or coronary artery bypass grafting $(\mathrm{CABG})$, and high $(\geq 33)$ where $\mathrm{CABG}$ is the preferred.

CAD was defined significant if there was $\geq 50 \%$ diameter stenosis in $\geq 1$ major coronary artery.

\section{Statistical analysis}

Data were statistically described in terms of median and interquartile range (IQR) for quantitative, while categorical variables were expressed as number and percentages when appropriate. Comparison between the study groups was done using Mann-Whitney U-test for numerical, Chi-square and Fisher's exact test for categorical data variables. Correlation between two numerical various variables was done using Pearson correlation coefficient (Spearman rho correlation coefficient equation for non-normal variables). P-values less than 0.05 were considered statistically significant. Statistical calculations were done using SPSS version 17.

\section{Results}

The study included 90 non-diabetic patients with documented 
Table 2. Prevalence of Single Vessel, Double Vessel and Triple Vessel CAD

\begin{tabular}{llll}
\hline No. of vessel involved & Group I (MAU negative) $(\mathbf{n}=\mathbf{6 2})$ & Group II (MAU positive) $(\mathbf{n = 2 8 )}$ & P-value* \\
\hline Single vessel, $\mathrm{n}(\%)$ & $39(62.9 \%)$ & $3(10.7 \%)$ & $<0.001$ \\
Double vessel, n (\%) & $15(24.1 \%)$ & $13(46.4 \%)$ & 0.033 \\
Triple vessel, $\mathrm{n}(\%)$ & $8(12.9 \%)$ & $12(42.8 \%)$ & 0.002 \\
\hline
\end{tabular}

${ }^{*} \mathrm{P}<0.05$ was considered significant.

Table 3. Correlation Between Microalbuminuria and Number of Vessels Affected

\begin{tabular}{lllll}
\hline Group & SVD, $\mathbf{n}(\%)$ & DVD, $\mathbf{n}(\%)$ & TVD, $\mathbf{n}(\%)$ & r* P-value \\
\hline Group I (MAU negative) $(\mathrm{n}=62)$ & $39(62.9 \%)$ & $15(24.1 \%)$ & $8(12.9 \%)$ & $\mathrm{r}=-0.035 ; \mathrm{P}=0.785$ \\
Group II (MAU positive) $(\mathrm{n}=28)$ & $3(10.7 \%)$ & $13(46.4 \%)$ & $12(42.8 \%)$ & $\mathrm{r}=0.094 ; \mathrm{P}<0.001$ \\
\hline
\end{tabular}

MAU: microalbuminuria; CAD: coronary artery disease; SVD: single vessel disease; DVD: double vessel disease; TVD: triple vessel disease. $r^{*}=$ Spearman rho correlation coefficient.

CAD by elective coronary angiography. The patients were classified into two groups based on the presence or absence of MAU: group I (MAU negative) consisted of patients with ACR level $<30 \mathrm{mg} / \mathrm{g}$ of creatinine (62 patients, $68.9 \%$ ); group II (MAU positive) consisted of patients with ACR level 30 $300 \mathrm{mg} / \mathrm{g}$ of creatinine (28 patients, $31.1 \%$ ).

\section{Demographic and clinical characteristics}

Demographic and clinical characteristics of all patients are shown in Table 1. Among patients with a positive MAU test, the median age was 54 years. There were no significant differences in the prevalence of hypertension, hypercholesterolemia, smoking and family history of CAD between the two groups.

\section{Prevalence of single vessel, double vessel and triple vessel CAD}

The distribution of CAD severity in the groups with and without MAU is presented in Table 2. The prevalence of double vessel CAD and triple vessel CAD was significantly higher in MAU positive group. Double vessel CAD was present in $24.1 \%$ of patients in group I, whereas it was present in $46.4 \%$ of patients in group II ( $\mathrm{P}=0.033)$. Of patients, $42.8 \%$ and $12.9 \%$ in group II and group I had triple vessel CAD respectively $(\mathrm{P}=0.002)$.

\section{Correlation between MAU and severity of CAD (in terms of number of vessels involved)}

In group I, the correlation between MAU and severity of CAD was not statistically significant $(\mathrm{r}=-0.035 ; \mathrm{P}=0.7850)$ (Table 3 ). On the other hand, presence of MAU exhibited a significant correlation with the severity of CAD $(r=0.094 ; \mathrm{P}<0.001)$ (Table 3).

\section{Median ACR level}

The median ACR level in group I was 23 and in group II was 135.9 and this was statistically significant $(\mathrm{P}<0.001)$. Also, there was significant difference in the median of ACR level among patients with single vessel disease (SVD), double vessel disease (DVD) and triple vessel disease (TVD) in group II (121 vs. 131 vs. $146, \mathrm{P}<0.001$ ) (Table 4).

\section{Relation between SYNTAX score and MAU}

There was statistically significant difference between patients with and those without MAU regarding their SYNTAX scores. Patients with MAU had higher SYNTAX scores compared to those without MAU ( $28 \pm 8$ vs. $21 \pm 6, \mathrm{P}<0.001)$, as shown in Table 5.

In both groups, the severity of CAD by SYNTAX score was evaluated as low score $\leq 22$ and intermediate or high score

Table 4. The Median ACR Level Among Patients With SVD, DVD and TVD in Group II

\begin{tabular}{lll}
\hline Vessel affected & ACR level (median) & P-value \\
\hline SVD & 121 & $<0.001$ (between all comparison)* \\
DVD & 131 & \\
TVD & 146 & \\
\hline
\end{tabular}

${ }^{*} \mathrm{P}<0.05$ was considered significant. In all comparisons (SVD vs. DVD, SVD vs. TVD, DVD vs. TVD), $P$ value was significant. 
Table 5. Median SYNTAX Score Between the Two Groups

\begin{tabular}{lll} 
& SYNTAX score, median \pm IQR & P-value \\
\hline Group I (MAU negative) $(\mathrm{n}=62)$ & $21 \pm 6$ & $<0.001$ \\
Group II (MAU positive) $(\mathrm{n}=28)$ & $28 \pm 8$ & \\
\hline
\end{tabular}

MAU: microalbuminuria; IQR: interquartile range. $\mathrm{P}<0.05$ was considered significant.

$>22$. In group I, 45 patients $(72.5 \%)$ had a low SYNTAX score $\leq 22$ and 17 patients $(27.4 \%)$ had an intermediate or high score $>22$. In group II, six patients $(21.4 \%)$ had a low SYNTAX score $\leq 22$ and 22 patients $(78.5 \%)$ had an intermediate or high score $>22$ (Table 6).

\section{Discussion}

Albumin excretion in the range of $30-300 \mathrm{mg} / \mathrm{g}$ of urinary creatinine is referred to as MAU. In the present study urinary ACR in spot urine sample was used to detect MAU, as it was shown to be equally sensitive and specific to 24-h urine collection method [13]. MAU is highly prevalent in several disease states. In this study, we found that the frequency of MAU was elevated in the study population $(31.1 \%)$ which is significantly higher as compared to the general population which ranges from $5 \%$ to $7 \%$ in previous studies $[14,15]$. Thus this study highlights that MAU is more frequent in non-diabetic patients with CAD than the general population and may be an important emerging risk marker for CAD. In the present study, there were no significant differences in the prevalence of hypertension, hypercholesterolemia, smoking and family history of CAD between the two groups. Differing from Gou et al [16], we did not find any relation between MAU with, hypercholesterolemia, cigarette smoking and hypertension. Although previous studies have reported the association between hypertension and MAU [17, 18], in the present investigation, we were not able to see a similar association. This diversity could be due to differences in sample size, race and geographic or nutritional factors.

The prevalence of double vessel CAD and triple vessel CAD was significantly higher in MAU positive group. The current study showed that patients with MAU have a greater atherosclerotic burden and a more severe CAD in the form of total number of vessels affected per patient than those without MAU. The results are in accordance with the previously reported findings [19-22]. In the present study, presence of MAU exhibited a significant correlation with the severity of CAD $(\mathrm{r}=$ 0.094; $\mathrm{P}<0.001$ ). Previous studies by Guo et al [16], Hoseini et al [21], and Al Saffar et al [22] also concluded that there was a positive correlation between severity of CAD and MAU in non- diabetic patients. The median ACR level in group I was 23 and in group II was 135.9 and this was statistically significant $(\mathrm{P}<$ 0.001). Hashim et al [20] in their study found a mean ACR of $131.8 \pm 66.2 \mathrm{mg} / \mathrm{g}$. In the present study, patients with MAU had higher SYNTAX scores compared to those without MAU (28 \pm 8 vs. $21 \pm 6, \mathrm{P}<0.001$ ), showing that presence of MAU was associated with more complex CAD. This finding was in agreement with previous reports $[19,23]$. The mechanism whereby MAU accelerates atherosclerosis is unclear. It is proposed that MAU indicates early and possibly reversible glomerular damage [4]. In non-diabetic persons with MAU, alterations in the extracellular matrix cause an increase in vascular permeability and this contributes to the development of endothelial dysfunction which promotes lipid influx into the vessel wall causing atherosclerotic changes [24]. It appears that aggressive treatment of MAU is beneficial in CAD patients. Several strategies are available to lower UAE. Widely known is the albuminuria-lowering effect of antihypertensive agents, which intervene with the renin angiotensin-aldosterone system. Ibsen et al [25] showed that a decrease in baseline albuminuria, which was more significant with losartan than with atenolol, results in significant reduction in cardiovascular events. Asselbergs et al [26] showed that the lowering of albuminuria with the ACEI fosinopril tended to be cardioprotective.

Gosling et al [27] and Haffner et al [28] considered MAU as an emerging cardiovascular risk factor in the non-diabetic patients. The present study agrees with these observations as it shows a significant MAU in non-diabetic CAD patients. This study has some limitations. First, it is a cross-sectional study, so a causal relationship cannot be established. Second, it is a single center study, with a small number of patients.

\section{Conclusion}

In our study, we found significantly high MAU levels in nondiabetic patients. The results of the present study indicate that non-diabetic patients with MAU have more extensive and complex angiographic CAD compared to those without MAU. Since the MAU is simple and relatively inexpensive investigation, early identification of MAU may influence the aggressiveness of management and ultimately the outcome of

Table 6. Relation Between SYNTAX Score and ACR

\begin{tabular}{llll}
\hline Urinary ACR & SYNTAX $\leq \mathbf{2 2}, \mathbf{n}(\mathbf{\%})$ & SYNTAX $>\mathbf{2 2}, \mathbf{n}(\mathbf{\%})$ & P-value \\
\hline Group I & $45(72.5 \%)$ & $17(27.4 \%)$ & $<0.001$ (both groups) \\
Group II & $6(21.4 \%)$ & $22(78.5 \%)$ & \\
\hline
\end{tabular}

ACR: albumin/creatinine ratio. $\mathrm{P}<0.05$ was considered significant. Also, when group I and group II where compared, patients with MAU had higher SYNTAX scores compared to those without MAU $(P<0.001)$. 
the disease.

\section{References}

1. Kuulasmaa K, Tunstall-Pedoe H, Dobson A, Fortmann S, Sans S, Tolonen H, Evans A, et al. Estimation of contribution of changes in classic risk factors to trends in coronary-event rates across the WHO MONICA Project populations. Lancet. 2000;355(9205):675-687.

2. Parving HH, Mogensen CE, Jensen HA, Evrin PE. Increased urinary albumin-excretion rate in benign essential hypertension. Lancet. 1974;1(7868):1190-1192.

3. Park HY, Schumock GT, Pickard AS, Akhras K. A structured review of the relationship between microalbuminuria and cardiovascular events in patients with diabetes mellitus and hypertension. Pharmacotherapy. 2003;23(12):1611-1616.

4. Bigazzi R, Bianchi S, Baldari D, Campese VM. Microalbuminuria predicts cardiovascular events and renal insufficiency in patients with essential hypertension. J Hypertens. 1998;16(9):1325-1333.

5. Romundstad S, Holmen J, Kvenild K, Hallan H, Ellekjaer H. Microalbuminuria and all-cause mortality in 2,089 apparently healthy individuals: a 4.4-year follow-up study. The Nord-Trondelag Health Study (HUNT), Norway. Am J Kidney Dis. 2003;42(3):466-473.

6. Klausen K, Borch-Johnsen K, Feldt-Rasmussen B, Jensen G, Clausen P, Scharling H, Appleyard M, et al. Very low levels of microalbuminuria are associated with increased risk of coronary heart disease and death independently of renal function, hypertension, and diabetes. Circulation. 2004;110(1):32-35.

7. Hillege HL, Fidler V, Diercks GF, van Gilst WH, de Zeeuw D, van Veldhuisen DJ, Gans RO, et al. Urinary albumin excretion predicts cardiovascular and noncardiovascular mortality in general population. Circulation. 2002;106(14):1777-1782.

8. Pedrinelli R, Penno G, Dell'Omo G, Bandinelli S, Giorgi D, Di Bello V, Navalesi R, et al. Microalbuminuria and transcapillary albumin leakage in essential hypertension. Hypertension. 1999;34(3):491-495.

9. Taddei S, Virdis A, Mattei P, Ghiadoni L, Sudano I, Arrighi P, Salvetti A. Lack of correlation between microalbuminuria and endothelial function in essential hypertensive patients. J Hypertens. 1995;13(9):1003-1008.

10. Bakris GC, Randall O, Rahman M, et al. For the African American Study of Kidney Disease (AASK) Study Group. Association between cardiovascular risk factors and glomerular filtration rate at baseline in the AASK trial. J Am SocNephrol. 1998;9:139.

11. Hoseinii VN, Tazaki O. Relationship between Microalbuminuria and severity of coronary artey disease in nondiabetic patients. Iran Cardiovasc Res J. 2008;4:234-237.

12. Sarnak MJ, Levey AS, Schoolwerth AC, Coresh J, Culleton B, Hamm LL, McCullough PA, et al. Kidney disease as a risk factor for development of cardiovascular disease: a statement from the American Heart Association Councils on Kidney in Cardiovascular Disease, High Blood
Pressure Research, Clinical Cardiology, and Epidemiology and Prevention. Circulation. 2003;108(17):21542169.

13. Eknoyan G, Hostetter T, Bakris GL, Hebert L, Levey AS, Parving HH, Steffes MW, et al. Proteinuria and other markers of chronic kidney disease: a position statement of the national kidney foundation (NKF) and the national institute of diabetes and digestive and kidney diseases (NIDDK). Am J Kidney Dis. 2003;42(4):617-622.

14. Atkins RC. The epidemiology of chronic kidney disease. Kidney Int Suppl. 2005;94:S14-18.

15. Hillege HL, Janssen WM, Bak AA, Diercks GF, Grobbee DE, Crijns HJ, Van Gilst WH, et al. Microalbuminuria is common, also in a nondiabetic, nonhypertensive population, and an independent indicator of cardiovascular risk factors and cardiovascular morbidity. J Intern Med. 2001;249(6):519-526.

16. Guo L, Cheng Y, Wang X, Pan Q, Li H, Zhang L, Wang Y. Association between microalbuminuria and cardiovascular disease in type 2 diabetes mellitus of the Beijing Han nationality. Acta Diabetol. 2012;49(Suppl 1):S65-71.

17. Damsgaard EM, Froland A, Jorgensen OD, Mogensen CE. Microalbuminuria as predictor of increased mortality in elderly people. BMJ. 1990;300(6720):297-300.

18. Yudkin JS, Forrest RD, Jackson CA. Microalbuminuria as predictor of vascular disease in non-diabetic subjects. Islington Diabetes Survey. Lancet. 1988;2(8610):530533.

19. Sukhija R, Aronow WS, Kakar P, Garza L, Sachdeva R, Sinha A, Mehta JL. Relation of microalbuminuria and coronary artery disease in patients with and without diabetes mellitus. Am J Cardiol. 2006;98(3):279-281.

20. Hashim R, Nisar S, urRehman K, et al. Microalbuminuria: association with ischemic heart disease in non-diabetics. J Ayub Med Coll Abbottabad. 2006;18(1):40-43.

21. Hoseini VN, Rasouli M. Microalbuminuria correlates with the prevalence and severity of coronary artery disease in non-diabetic patients. Cardiol J. 2009;16(2):142145.

22. Al-Saffar HB, Nassir H, Mitchell A, Philipp S. Microalbuminuria in non-diabetic patients with unstable angina/ non ST-segment elevation myocardial infarction. BMC Res Notes. 2015;8:371.

23. Lekatsas I, Kranidis A, Ioannidis G, Kalofoutis C, Tavernarakis A, Thalassinos N, Kalofoutis A, et al. Comparison of the extent and severity of coronary artery disease in patients with acute myocardial infarction with and without microalbuminuria. Am J Cardiol. 2004;94(3):334-337.

24. Schmitz A. Microalbuminuria, blood pressure, metabolic control, and renal involvement: longitudinal studies in white non-insulin-dependent diabetic patients. Am J Hypertens. 1997;10(9 Pt 2):189S-197S.

25. Ibsen $\mathrm{H}$, Wachtell $\mathrm{K}$, Olsen $\mathrm{MH}$, Borch-Johnsen $\mathrm{K}$, Lindholm LH, Mogensen CE, Dahlof B, et al. Does albuminuria predict cardiovascular outcome on treatment with losartan versus atenolol in hypertension with left ventricular hypertrophy? A LIFE substudy. J Hypertens. 2004;22(9):1805-1811.

26. Asselbergs FW, Diercks GF, Hillege HL, van Boven 
AJ, Janssen WM, Voors AA, de Zeeuw D, et al. Effects of fosinopril and pravastatin on cardiovascular events in subjects with microalbuminuria. Circulation. 2004;110(18):2809-2816.

27. Gosling P. Microalbuminuria and cardiovascular risk: a word of caution. J Hum Hypertens. 1998;12(4):211-213.

28. Haffner SM, Stern MP, Gruber MK, Hazuda HP, Mitchell $\mathrm{BD}$, Patterson JK. Microalbuminuria. Potential marker for increased cardiovascular risk factors in nondiabetic subjects? Arteriosclerosis. 1990;10(5):727-731. 